\title{
CONVENCIÓN SOBRE LA PROTECCIÓN Y PROMOCIÓN DE LA DIVERSIDAD DE LAS EXPRESIONES CULTURALES
}

París, 20 de octubre de 2005

La Conferencia General de la Organización de las Naciones Unidas para la Educación, la Ciencia y la Cultura, en su $33^{a}$ reunión, celebrada en París del 3 al 21 de octubre de 2005,

Afirmando que la diversidad cultural es una característica esencial de la humanidad,

Consciente de que la diversidad cultural constituye un patrimonio común de la humanidad que debe valorarse y preservarse en provecho de todos,

Consciente de que la diversidad cultural crea un mundo rico y variado que acrecienta la gama de posibilidades y nutre las capacidades y los valores humanos, y constituye, por lo tanto, uno de los principales motores del desarrollo sostenible de las comunidades, los pueblos y las naciones,

Recordando que la diversidad cultural, tal y como prospera en un marco de democracia, tolerancia, justicia social y respeto mutuo entre los pueblos y las culturas, es indispensable para la paz y la seguridad en el plano local, nacional e internacional,

Encomiando la importancia de la diversidad cultural para la plena realización de los derechos humanos y libertades fundamentales proclamados en la Declaración Universal de Derechos Humanos y otros instrumentos universalmente reconocidos,

Destacando la necesidad de incorporar la cultura como elemento estratégico a las políticas de desarrollo nacionales e internacionales, así como a la cooperación internacional para el desarrollo, teniendo en cuenta asimismo la Declaración del Milenio de las Naciones Unidas (2000), con su especial hincapié en la erradicación de la pobreza,

Considerando que la cultura adquiere formas diversas a través del tiempo y el espacio y que esta diversidad se manifiesta en la originalidad y la pluralidad de las identidades y en las expresiones culturales de los pueblos y sociedades que forman la humanidad,
Reconociendo la importancia de los conocimientos tradicionales como fuente de riqueza inmaterial y material, en particular los sistemas de conocimieto de los pueblos autóctonos y su contribución positiva al desarrollo sostenible, así como la necesidad de garantizar su protección y promoción de manera adecuada,

Reconociendo la necesidad de adoptar medidas para proteger la diversidad de las expresiones culturales y sus contenidos, especialmente en situaciones en las que las expresiones culturales pueden correr peligro de extinción o de grave menoscabo,

Destacando la importancia de la cultura para la cohesión social en general y, en particular, las posibilidades que encierra para la mejora de la condición de la mujer y su papel en la sociedad,

Consciente de que la diversidad cultural se fortalece mediante la libre circulación de las ideas y se nutre de los intercambios y las interacciones constantes entre las culturas,

Reiterando que la libertad de pensamiento, expresión e información, así como la diversidad de los medios de comunicación social, posibilitan el florecimiento de las expresiones culturales en las sociedades,

Reconociendo que la diversidad de expresiones culturales, comprendidas las expresiones culturales tradicionales, es un factor importante que permite a los pueblos y las personas expresar y compartir con otros sus ideas y valores,

Recordando que la diversidad lingüística es un elemento fundamental de la diversidad cultural, y reafirmando el papel fundamental que desempeña la educación en la protección y promoción de las expresiones culturales,

Teniendo en cuenta la importancia de la vitalidad de las culturas para todos, especialmente en el ca- 
so de las personas pertenecientes a minorías y de los pueblos autóctonos, tal y como se manifiesta en su libertad de crear, difundir y distribuir sus expresiones culturales tradicionales, así como su derecho a tener acceso a ellas a fin de aprovecharlas para su propio desarrollo,

Subrayando la función esencial de la interacción y la creatividad culturales, que nutren y renuevan las expresiones culturales, y fortalecen la función desempeñada por quienes participan en el desarrollo de la cultura para el progreso de la sociedad en general,

Reconociendo la importancia de los derechos de propiedad intelectual para sostener a quienes participan en la creatividad cultural,

Persuadida de que las actividades, los bienes y los servicios culturales son de índole a la vez económica y cultural, porque son portadores de identidades, valores y significados, y por consiguiente no deben tratarse como si sólo tuviesen un valor comercial,

Observando que los procesos de mundialización facilitados por la evolución rápida de las tecnologías de la información y la comunicación, pese a que crean condiciones inéditas para que se intensifique la interacción entre las culturas, constituyen también un desafío para la diversidad cultural, especialmente en lo que respecta a los riesgos de desequilibrios entre países ricos y países pobres,

Consciente de que la UNESCO tiene asignado el cometido específico de garantizar el respeto de la diversidad de culturas y recomendar los acuerdos internacionales que estime convenientes para facilitar la libre circulación de las ideas por medio de la palabra y de la imagen,

Teniendo en cuenta las disposiciones de los instrumentos internacionales aprobados por la UNESCO sobre la diversidad cultural y el ejercicio de los derechos culturales, en particular la Declaración Universal sobre la Diversidad Cultural de 2001,

Aprueba, el 20 de octubre de 2005, la presente Convención.
I. Objetivos y principios rectores

Artículo 1. Objetivos

Los objetivos de la presente Convención son:

a) proteger y promover la diversidad de las expresiones culturales;

b) crear las condiciones para que las culturas puedan prosperar y mantener interacciones libremente de forma mutuamente provechosa;

c) fomentar el diálogo entre culturas a fin de garantizar intercambios culturales más amplios y equilibrados en el mundo en pro del respeto intercultural y una cultura de paz;

d) fomentar la interculturalidad con el fin de desarrollar la interacción cultural, con el espíritu de construir puentes entre los pueblos;

e) promover el respeto de la diversidad de las expresiones culturales y hacer cobrar conciencia de su valor en el plano local, nacional e internacional;

f) reafirmar la importancia del vínculo existente entre la cultura y el desarrollo para todos los países, en especial los países en desarrollo, y apoyar las actividades realizadas en el plano nacional e internacional para que se reconozca el auténtico valor de ese vínculo;

g) reconocer la índole específica de las actividades y los bienes y servicios culturales en su calidad de portadores de identidad, valores y significado;

h) reiterar los derechos soberanos de los Estados a conservar, adoptar y aplicar las políticas y medidas que estimen necesarias para proteger y promover la diversidad de las expresiones culturales en sus respectivos territorios;

i) fortalecer la cooperación y solidaridad internacionales en un espíritu de colaboración, a fin de reforzar, en particular, las capacidades de los países en desarrollo con objeto de proteger y promover la diversidad de las expresiones culturales.

Artículo 2. Principios rectores

1. Principio de respeto de los derechos humanos y las libertades fundamentales 
Sólo se podrá proteger y promover la diversidad cultural si se garantizan los derechos humanos y las libertades fundamentales como la libertad de expresión, información y comunicación, así como la posibilidad de que las personas escojan sus expresiones culturales. Nadie podrá invocar las disposiciones de la presente Convención para atentar contra los derechos humanos y las libertades fundamentales proclamados en la Declaración Universal de Derechos Humanos y garantizados por el derecho internacional, o para limitar su ámbito de aplicación.

\section{Principio de soberanía}

De conformidad con la Carta de las Naciones Unidas y los principios del derecho internacional, los Estados tienen el derecho soberano de adoptar medidas y políticas para proteger y promover la diversidad de las expresiones culturales en sus respectivos territorios.

3. Principio de igual dignidad y respeto de todas las culturas

La protección y la promoción de la diversidad de las expresiones culturales presuponen el reconocimiento de la igual dignidad de todas las culturas y el respeto de ellas, comprendidas las culturas de las personas pertenecientes a minorías y las de los pueblos autóctonos.

4. Principio de solidaridad y cooperación internacionales

La cooperación y la solidaridad internacionales deberán estar encaminadas a permitir a todos los países, en especial los países en desarrollo, crear y reforzar sus medios de expresión cultural, comprendidas sus industrias culturales, nacientes 0 establecidas, en el plano local, nacional e internacional.

5. Principio de complementariedad de los aspectos económicos y culturales del desarrollo

Habida cuenta de que la cultura es uno de los principales motores del desarrollo, los aspectos culturales de éste son tan importantes como sus aspectos económicos, respecto de los cuales los individuos y los pueblos tienen el derecho fundamental de participación y disfrute.

\section{Principio de desarrollo sostenible}

La diversidad cultural es una gran riqueza para las personas y las sociedades. La protección, la promoción y el mantenimiento de la diversidad cultural son una condición esencial para un desarrollo sostenible en beneficio de las generaciones actuales y futuras.

\section{Principio de acceso equitativo}

El acceso equitativo a una gama rica y diversificada de expresiones culturales procedentes de todas las partes del mundo y el acceso de las culturas a los medios de expresión y difusión son elementos importantes para valorizar la diversidad cultural y propiciar el entendimiento mutuo.

8. Principio de apertura y equilibrio

Cuando los Estados adopten medidas para respaldar la diversidad de las expresiones culturales, procurarán promover de manera adecuada una apertura a las demás culturas del mundo y velarán por que esas medidas se orienten a alcanzar los objetivos perseguidos por la presente Convención.

II. Ámbito de aplicación

Artículo 3. Ámbito de aplicación

Esta Convención se aplicará a las políticas y medidas que adopten las Partes en relación con la protección y promoción de la diversidad de las expresiones culturales.

III. Definiciones

Artículo 4. Definiciones

A efectos de la presente Convención:

1. Diversidad cultural

La "diversidad cultural" se refiere a la multiplicidad de formas en que se expresan las culturas de los grupos y sociedades. Estas expresiones se transmiten dentro y entre los grupos y las sociedades.

La diversidad cultural se manifiesta no sólo en las diversas formas en que se expresa, enriquece y transmite el patrimonio cultural de la humanidad mediante la variedad de expresiones culturales, si- 
no también a través de distintos modos de creación artística, producción, difusión, distribución y disfrute de las expresiones culturales, cualesquiera que sean los medios y tecnologías utilizados.

\section{Contenido cultural}

El "contenido cultural" se refiere al sentido simbólico, la dimensión artística y los valores culturales que emanan de las identidades culturales o las expresan.

\section{Expresiones culturales}

Las "expresiones culturales" son las expresiones resultantes de la creatividad de personas, grupos y sociedades, que poseen un contenido cultural.

\section{Actividades, bienes y servicios culturales}

Las "actividades, bienes y servicios culturales" se refieren a las actividades, los bienes y los servicios que, considerados desde el punto de vista de su calidad, utilización o finalidad específicas, encarnan o transmiten expresiones culturales, independientemente del valor comercial que puedan tener. Las actividades culturales pueden constituir una finalidad de por sí, o contribuir a la producción de bienes y servicios culturales.

\section{Industrias culturales}

Las "industrias culturales" se refieren a todas aquellas industrias que producen y distribuyen bienes o servicios culturales, tal como se definen en el párrafo 4 supra.

\section{Políticas y medidas culturales}

Las "políticas y medidas culturales" se refieren a las políticas y medidas relativas a la cultura, ya sean éstas locales, nacionales, regionales o internacionales, que están centradas en la cultura como tal, o cuya finalidad es ejercer un efecto directo en las expresiones culturales de las personas, grupos - sociedades, en particular la creación, producción, difusión y distribución de las actividades y los bienes y servicios culturales y el acceso a ellos.

\section{Protección}

La "protección" significa la adopción de medidas encaminadas a la preservación, salvaguardia y en- riquecimiento de la diversidad de las expresiones culturales.

"Proteger" significa adoptar tales medidas.

8. Interculturalidad

La "interculturalidad" se refiere a la presencia e interacción equitativa de diversas culturas y la posibilidad de generar expresiones culturales compartidas, adquiridas por medio del diálogo y de una actitud de respeto mutuo.

IV. Derechos y obligaciones de las partes

Artículo 5. Norma general relativa a los derechos y obligaciones

1. Las Partes, de conformidad con la Carta de las Naciones Unidas, los principios del derecho internacional y los instrumentos de derechos humanos universalmente reconocidos, reafirman su derecho soberano a formular y aplicar sus políticas culturales y a adoptar medidas para proteger y promover la diversidad de las expresiones culturales, así como a reforzar la cooperación internacional para lograr los objetivos de la presente Convención.

2. Cuando una Parte aplique políticas y adopte medidas para proteger y promover la diversidad de las expresiones culturales en su territorio, tales políticas y medidas deberán ser coherentes con las disposiciones de la presente Convención.

Artículo 6. Derechos de las Partes en el plano nacional

1. En el marco de sus políticas y medidas culturales, tal como se definen en el párrafo 6 del Artículo 4, y teniendo en cuenta sus circunstancias y necesidades particulares, las Partes podrán adoptar medidas para proteger y promover la diversidad de las expresiones culturales en sus respectivos territorios.

\section{Esas medidas pueden consistir en:}

a) medidas reglamentarias encaminadas a la protección y promoción de la diversidad de las expresiones culturales;

b) medidas que brinden oportunidades, de modo apropiado, a las actividades y los bienes y servicios 
culturales nacionales, entre todas las actividades, bienes y servicios culturales disponibles dentro de territorio nacional, para su creación, producción, distribución, difusión y disfrute, comprendidas disposiciones relativas a la lengua utilizada para tales actividades, bienes y servicios;

c) medidas encaminadas a proporcionar a las industrias culturales independientes nacionales y las actividades del sector no estructurado un acceso efectivo a los medios de producción, difusión y distribución de bienes y servicios culturales;

d) medidas destinadas a conceder asistencia financiera pública;

e) medidas encaminadas a alentar a organizaciones sin fines de lucro, así como a entidades públicas y privadas, artistas y otros profesionales de la cultura, a impulsar y promover el libre intercambio y circulación de ideas, expresiones culturales y actividades, bienes y servicios culturales, y a estimular en sus actividades el espíritu creativo y el espíritu de empresa;

f) medidas destinadas a crear y apoyar de manera adecuada las instituciones de servicio público pertinentes;

g) medidas encaminadas a respaldar y apoyar a los artistas y demás personas que participan en la creación de expresiones culturales;

h) medidas destinadas a promover la diversidad de los medios de comunicación social, comprendida la promoción del servicio público de radiodifusión.

Artículo 7. Medidas para promover las expresiones culturales

1. Las Partes procurarán crear en su territorio un entorno que incite a las personas y a los grupos a:

a) crear, producir, difundir y distribuir sus propias expresiones culturales, y tener acceso a ellas, prestando la debida atención a las circunstancias y necesidades especiales de las mujeres y de distintos grupos sociales, comprendidas las personas pertenecientes a minorías y los pueblos autóctonos;

b) tener acceso a las diversas expresiones culturales procedentes de su territorio y de los demás países del mundo.
2. Las Partes procurarán también que se reconozca la importante contribución de los artistas, de todas las personas que participan en el proceso creativo, de las comunidades culturales y de las organizaciones que los apoyan en su trabajo, así como el papel fundamental que desempeñan, que es alimentar la diversidad de las expresiones culturales.

Artículo 8. Medidas para proteger las expresiones culturales

1. Sin periuicio de lo dispuesto en los Artículos 5 y 6, una Parte podrá determinar si hay situaciones especiales en que las expresiones culturales en su territorio corren riesgo de extinción, o son objeto de una grave amenaza o requieren algún tipo de medida urgente de salvaguardia.

2. Las Partes podrán adoptar cuantas medidas consideren necesarias para proteger y preservar las expresiones culturales en las situaciones a las que se hace referencia en el párrafo 1 , de conformidad con las disposiciones de la presente Convención.

3. Las Partes informarán al Comité Intergubernamental mencionado en el Artículo 23 de todas las medidas adoptadas para enfrentarse con la situación, y el Comité podrá formular las recomendaciones que convenga.

Artículo 9. Intercambio de información y transparencia

Las Partes:

a) proporcionarán cada cuatro años, en informes a la UNESCO, información apropiada acerca de las medidas que hayan adoptado para proteger y promover la diversidad de las expresiones culturales en sus respectivos territorios y en el plano internacional;

b) designarán un punto de contacto encargado del intercambio de información relativa a la presente Convención;

c) comunicarán e intercambiarán información sobre la protección y promoción de la diversidad de las expresiones culturales. 
Artículo 10. Educación y sensibilización del público

Las Partes deberán:

a) propiciar y promover el entendimiento de la importancia que revisten la protección y fomento de la diversidad de las expresiones culturales mediante, entre otros medios, programas de educación y mayor sensibilización del público;

b) cooperar con otras Partes y organizaciones internacionales y regionales para alcanzar los objetivos del presente artículo;

c) esforzarse por alentar la creatividad y fortalecer las capacidades de producción mediante el establecimiento de programas de educación, formación e intercambios en el ámbito de las industrias culturales. Estas medidas deberán aplicarse de manera que no tengan repercusiones negativas en las formas tradicionales de producción.

Artículo 11 - Participación de la sociedad civil

Las Partes reconocen el papel fundamental que desempeña la sociedad civil en la protección y promoción de la diversidad de las expresiones culturales. Las Partes fomentarán la participación activa de la sociedad civil en sus esfuerzos por alcanzar los objetivos de la presente Convención.

Artículo 12. Promoción de la cooperación internacional

Las Partes procurarán fortalecer su cooperación bilateral, regional e internacional para crear condiciones que faciliten la promoción de la diversidad de las expresiones culturales, teniendo especialmente en cuenta las situaciones contempladas en los Artículos 8 y 17, en particular con miras a:

a) facilitar el diálogo entre las Partes sobre la política cultural;

b) reforzar las capacidades estratégicas y de gestión del sector público en las instituciones culturales públicas, mediante los intercambios profesionales y culturales internacionales y el aprovechamiento compartido de las mejores prácticas;

c) reforzar las asociaciones con la sociedad civil, las organizaciones no gubernamentales y el sector privado, y entre todas estas entidades, para fomen- tar y promover la diversidad de las expresiones culturales;

d) promover el uso de nuevas tecnologías y alentar la colaboración para extender el intercambio de información y el entendimiento cultural, y fomentar la diversidad de las expresiones culturales;

e) fomentar la firma de acuerdos de coproducción y codistribución.

Artículo 13. Integración de la cultura en el desarrollo sostenible

Las Partes se esforzarán por integrar la cultura en sus políticas de desarrollo a todos los niveles a fin de crear condiciones propicias para el desarrollo sostenible $y$, en este marco, fomentar los aspectos vinculados a la protección y promoción de la diversidad de las expresiones culturales.

Artículo 14. Cooperación para el desarrollo

Las Partes se esforzarán por apoyar la cooperación para el desarrollo sostenible y la reducción de la pobreza, especialmente por lo que respecta a las necesidades específicas de los países en desarrollo, a fin de propiciar el surgimiento de un sector cultural dinámico por los siguientes medios, entre otros:

a) el fortalecimiento de las industrias culturales en los países en desarrollo:

I) creando y reforzando las capacidades de los países en desarrollo en materia de producción y difusión culturales;

II) facilitando un amplio acceso de sus actividades, bienes y servicios culturales al mercado mundial y a las redes de distribución internacionales;

III) propiciando el surgimiento de mercados locales y regionales viables;

IV) adoptando, cuando sea posible, medidas adecuadas en los países desarrollados para facilitar el acceso a su territorio de las actividades, los bienes y los servicios culturales procedentes de países en desarrollo;

V) prestando apoyo al trabajo creativo y facilitando, en la medida de lo posible, la movilidad de los 
artistas del mundo en desarrollo;

VI) alentando una colaboración adecuada entre países desarrollados y en desarrollo, en particular en los ámbitos de la música y el cine;

b) la creación de capacidades mediante el intercambio de información, experiencias y competencias, así como mediante la formación de recursos humanos en los países en desarrollo, tanto en el sector público como en el privado, especialmente en materia de capacidades estratégicas y de gestión, de elaboración y aplicación de políticas, de promoción de la distribución de bienes y servicios culturales, de fomento de pequeñas y medianas empresas y microempresas, de utilización de tecnología y de desarrollo y transferencia de competencias;

c) la transferencia de técnicas y conocimientos prácticos mediante la introducción de incentivos apropiados, especialmente en el campo de las industrias y empresas culturales;

d) el apoyo financiero mediante:

I) la creación de un Fondo Internacional para la Diversidad Cultural de conformidad con lo previsto en el Artículo 18;

II) el suministro de asistencia oficial al desarrollo, según proceda, comprendido el de ayuda técnica, a fin de estimular y apoyar la creatividad;

III) otras modalidades de asistencia financiera, tales como préstamos con tipos de interés bajos, subvenciones y otros mecanismos de financiación.

Artículo 15. Modalidades de colaboración

Las Partes alentarán la creación de asociaciones entre el sector público, el privado y organismos sin fines lucrativos, así como dentro de cada uno de ellos, a fin de cooperar con los países en desarrollo en el fortalecimiento de sus capacidades con vistas a proteger y promover la diversidad de las expresiones culturales. Estas asociaciones innovadoras harán hincapié, en función de las necesidades prácticas de los países en desarrollo, en el fomento de infraestructuras, recursos humanos y políticas, así como en el intercambio de actividades, bienes y servicios culturales.
Artículo 16. Trato preferente a los países en desarrollo

Los países desarrollados facilitarán los intercambios culturales con los países en desarrollo, otorgando por conducto de los marcos institucionales y jurídicos adecuados un trato preferente a los artistas y otros profesionales de la cultura de los países en desarrollo, así como a los bienes y servicios culturales procedentes de ellos.

Artículo 17. Cooperación internacional en situaciones de grave peligro para las expresiones culturales

Las Partes cooperarán para prestarse asistencia mutua, otorgando una especial atención a los países en desarrollo, en las situaciones contempladas en el Artículo 8.

Artículo 18. Fondo Internacional para la Diversidad Cultural

1. Queda establecido un Fondo Internacional para la Diversidad Cultural, denominado en adelante "el Fondo".

2. El Fondo estará constituido por fondos fiduciarios, de conformidad con el Reglamento Financiero de la UNESCO.

3. Los recursos del Fondo estarán constituidos por:

a) las contribuciones voluntarias de las Partes;

b) los recursos financieros que la Conferencia General de la UNESCO asigne a tal fin;

c) las contribuciones, donaciones o legados que puedan hacer otros Estados, organismos y programas del sistema de las Naciones Unidas, organizaciones regionales o internacionales, entidades públicas o privadas y particulares;

d) todo interés devengado por los recursos del Fondo;

e) el producto de las colectas y la recaudación de eventos organizados en beneficio del Fondo;

f) todos los demás recursos autorizados por el Reglamento del Fondo. 
4. La utilización de los recursos del Fondo por parte del Comité Intergubernamental se decidirá en función de las orientaciones que imparta la Conferencia de las Partes mencionada en el Artículo 22.

5. El Comité Intergubernamental podrá aceptar contribuciones $u$ otro tipo de ayudas con finalidad general o específica que estén vinculadas a proyectos concretos, siempre y cuando éstos cuenten con su aprobación.

6. Las contribuciones al Fondo no podrán estar supeditadas a condiciones políticas, económicas ni de otro tipo que sean incompatibles con los objetivos perseguidos por la presente Convención.

\section{7.}

Las Partes aportarán contribuciones voluntarias periódicas para la aplicación de la presente Convención.

Artículo 19. Intercambio, análisis y difusión de información

1. Las Partes acuerdan intercambiar información y compartir conocimientos especializados sobre acopio de información y estadísticas relativas a la diversidad de las expresiones culturales, así como sobre las mejores prácticas para su protección y promoción.

2. La UNESCO facilitará, gracias a la utilización de los mecanismos existentes en la Secretaría, el acopio, análisis y difusión de todas las informaciones, estadísticas y mejores prácticas pertinentes.

3. Además, la UNESCO creará y mantendrá actualizado un banco de datos sobre los distintos sectores y organismos gubernamentales, privados y no lucrativos, que actúan en el ámbito de las expresiones culturales.

4. Para facilitar el acopio de información, la UNES$\mathrm{CO}$ prestará una atención especial a la creación de capacidades y competencias especializadas en las Partes que formulen una solicitud de ayuda a este respecto.

5. El acopio de información al que se refiere el presente artículo complementará la información a la que se hace referencia en el Artículo 9.

\section{Relaciones con otros instrumentos}

Artículo 20. Relaciones con otros instrumentos: potenciación mutua, complementariedad y no subordinación

1. Las Partes reconocen que deben cumplir de buena fe con las obligaciones que les incumben en virtud de la presente Convención y de los demás tratados en los que son Parte. En consecuencia, sin subordinar esta Convención a los demás tratados:

a) fomentarán la potenciación mutua entre la presente Convención y los demás tratados en los que son Parte;

b) cuando interpreten y apliquen los demás tratados en los que son Parte o contraigan otras obligaciones internacionales, tendrán en cuenta las disposiciones pertinentes de la presente Convención.

2. Ninguna disposición de la presente Convención podrá interpretarse como una modificación de los derechos y obligaciones de las Partes que emanen de otros tratados internacionales en los que sean parte.

Artículo 21. Consultas y coordinación internacionales

Las Partes se comprometen a promover los objetivos y principios de la presente Convención en otros foros internacionales. A tal efecto, las Partes se consultarán, cuando proceda, teniendo presentes esos objetivos y principios.

\section{VI. Órganos de la Convención}

Artículo 22. Conferencia de las Partes

1. Se establecerá una Conferencia de las Partes. La Conferencia de las Partes será el órgano plenario y supremo de la presente Convención.

2. La Conferencia de las Partes celebrará una reunión ordinaria cada dos años en concomitancia, siempre y cuando sea posible, con la Conferencia General de la UNESCO. Podrá reunirse con carácter extraordinario cuando así lo decida, o cuando el Comité Intergubernamental reciba una petición en tal sentido de un tercio de las Partes por lo menos. 
3. La Conferencia de las Partes aprobará su propio reglamento.

4. Corresponderán a la Conferencia de las Partes, entre otras, las siguientes funciones:

a) elegir a los miembros del Comité Intergubernamental;

b) recibir y examinar los informes de las Partes en la presente Convención transmitidos por el Comité Intergubernamental;

c) aprobar las orientaciones prácticas que el Comité Intergubernamental haya preparado a petición de la Conferencia;

d) adoptar cualquier otra medida que considere necesaria para el logro de los objetivos de la presente Convención.

Artículo 23. Comité Intergubernamental

1. Se establecerá en la UNESCO un Comité Intergubernamental para la Protección y la Promoción de la Diversidad de las Expresiones Culturales, denominado en lo sucesivo "el Comité Intergubernamental", que comprenderá representantes de 18 Estados Parte en la Convención, elegidos por la Conferencia de las Partes para desempeñar un mandato de cuatro años tras la entrada en vigor de la presente Convención de conformidad con el Artículo 29.

2. El Comité Intergubernamental celebrará una reunión anual.

3. El Comité Intergubernamental funcionará bajo la autoridad de la Conferencia de las Partes, cumpliendo sus orientaciones y rindiéndole cuentas de sus actividades.

4. El número de miembros del Comité Intergubernamental pasará a 24 cuando el número de Partes en la Convención ascienda a 50.

5. La elección de los miembros del Comité Intergubernamental deberá basarse en los principios de la representación geográfica equitativa y la rotación.

6. Sin periuicio de las demás atribuciones que se le confieren en la presente Convención, las funciones del Comité Intergubernamental serán las siguientes: a) promover los objetivos de la Convención y fomentar y supervisar su aplicación;

b) preparar y someter a la aprobación de la Conferencia de las Partes orientaciones prácticas, cuando ésta lo solicite, para el cumplimiento y aplicación de las disposiciones de la Convención;

c) transmitir a la Conferencia de las Partes informes de las Partes, junto con sus observaciones y un resumen del contenido;

d) formular las recomendaciones apropiadas en los casos que las Partes en la Convención sometan a su atención de conformidad con las disposiciones pertinentes de la Convención, y en particular su $\mathrm{Ar}$ tículo 8;

e) establecer procedimientos y otros mecanismos de consulta para promover los objetivos y principios de la presente Convención en otros foros internacionales;

f) realizar cualquier otra tarea que le pueda pedir la Conferencia de las Partes.

7. El Comité Intergubernamental, de conformidad con su Reglamento, podrá invitar en todo momento a entidades públicas o privadas y a particulares a participar en sus reuniones para consultarlos sobre cuestiones específicas.

8.

El Comité Intergubernamental elaborará su propio Reglamento y lo someterá a la aprobación de la Conferencia de las Partes.

Artículo 24. Secretaría de la UNESCO

1. Los órganos de la Convención estarán secundados por la Secretaría de la UNESCO.

2. La Secretaría preparará los documentos de la Conferencia de las Partes y del Comité Intergubernamental, así como los proyectos de los órdenes del día de sus reuniones, y coadyuvará a la aplicación de sus decisiones e informará sobre dicha aplicación.

\section{Disposiciones finales}

Artículo 25. Solución de controversias 
1. En caso de controversia acerca de la interpretación o aplicación de la presente Convención, las Partes procurarán resolverla mediante negociaciones.

2. Si las Partes interesadas no llegaran a un acuerdo mediante negociaciones, podrán recurrir conjuntamente a los buenos oficios o la mediación de una tercera parte.

3. Cuando no se haya recurrido a los buenos oficios o la mediación o no se haya logrado una solución mediante negociaciones, buenos oficios o mediación, una Parte podrá recurrir a la conciliación de conformidad con el procedimiento que figura en el Anexo de la presente Convención. Las Partes examinarán de buena fe la propuesta que formule la Comisión de Conciliación para solucionar la controversia.

4. En el momento de la ratificación, aceptación, aprobación o adhesión, cada Parte podrá declarar que no reconoce el procedimiento de conciliación previsto supra. Toda Parte que haya efectuado esa declaración podrá retirarla en cualquier momento mediante una notificación dirigida al Director General de la UNESCO.

Artículo 26. Ratificación, aceptación, aprobación o adhesión por parte de los Estados Miembros

1. La presente Convención estará sujeta a la ratificación, aceptación, aprobación o adhesión de los Estados Miembros de la UNESCO, de conformidad con sus respectivos procedimientos constitucionales.

2. Los instrumentos de ratificación, aceptación, aprobación o adhesión se depositarán ante el Director General de la UNESCO.

Artículo 27. Adhesión

1. La presente Convención quedará abierta a la adhesión de todo Estado que no sea miembro de la UNESCO, pero que pertenezca a las Naciones Unidas o a uno de sus organismos especializados y que haya sido invitado por la Conferencia General de la Organización a adherirse a la Convención.

2. La presente Convención quedará abierta asimismo a la adhesión de los territorios que gocen de plena autonomía interna reconocida como tal por las Naciones Unidas pero que no hayan alcanzado la plena independencia de conformidad con la Resolución 1514 (XV) de la Asamblea General, y que tengan competencia sobre las materias regidas por esta Convención, incluida la de suscribir tratados en relación con ellas.

3. Se aplicarán las siguientes disposiciones a las organizaciones de integración económica regional:

a) la presente Convención quedará abierta asimismo a la adhesión de toda organización de integración económica regional, estando ésta a reserva de lo dispuesto en los apartados siguientes, vinculada por las disposiciones de la presente Convención de igual manera que los Estados Parte;

b) de ser uno o varios Estados Miembros de una organización de ese tipo Partes en la presente Convención, esa organización y ese o esos Estados Miembros decidirán cuáles son sus responsabilidades respectivas en lo referente al cumplimiento de sus obligaciones en el marco de la presente Convención. Ese reparto de responsabilidades surtirá efecto una vez finalizado el procedimiento de notificación previsto en el apartado c) infra. La organización y sus Estados Miembros no estarán facultados para ejercer concomitantemente los derechos que emanan de la presente Convención. Además, para ejercer el derecho de voto en sus ámbitos de competencia, la organización de integración económica regional dispondrá de un número de votos igual al de sus Estados Miembros que sean Parte en la presente Convención. La organización no ejercerá el derecho de voto si sus Estados Miembros lo ejercen, y viceversa;

c) la organización de integración económica regional y el o los Estados Miembros de la misma que hayan acordado el reparto de responsabilidades previsto en el apartado b) supra informarán de éste a las Partes, de la siguiente manera:

I) en su instrumento de adhesión dicha organización declarará con precisión cuál es el reparto de responsabilidades con respecto a las materias regidas por la presente Convención;

II) de haber una modificación ulterior de las responsabilidades respectivas, la organización de integración económica regional informará al depositario de toda propuesta de modificación de esas responsabilidades, y éste informará a su vez de ello a las Partes; 
d) se presume que los Estados Miembros de una organización de integración económica regional que hayan llegado a ser Partes en la Convención siguen siendo competentes en todos los ámbitos que no hayan sido objeto de una transferencia de competencia a la organización, expresamente declarada o señalada al depositario;

e) se entiende por "organización de integración económica regional" toda organización constituida por Estados soberanos miembros de las Naciones Unidas o de uno de sus organismos especializados, a la que esos Estados han transferido sus competencias en ámbitos regidos por esta Convención y que ha sido debidamente autorizada, de conformidad con sus procedimientos internos, a ser Parte en la Convención.

4. El instrumento de adhesión se depositará ante el Director General de la UNESCO.

Artículo 28. Punto de contacto

Cuando llegue a ser Parte en la presente Convención, cada Parte designará el punto de contacto mencionado en el Artículo 9.

Artículo 29. Entrada en vigor

1. La presente Convención entrará en vigor tres meses después de la fecha de depósito del trigésimo instrumento de ratificación, aceptación, aprobación o adhesión, pero sólo para los Estados o las organizaciones de integración económica regional que hayan depositado sus respectivos instrumentos de ratificación, aceptación, aprobación o adhesión en esa fecha o anteriormente. Para las demás Partes, entrará en vigor tres meses después de efectuado el depósito de su instrumento de ratificación, aceptación, aprobación o adhesión.

2. A efectos del presente artículo, no se considerará que los instrumentos de cualquier tipo depositados por una organización de integración económica regional vienen a añadirse a los instrumentos ya depositados por sus Estados Miembros.

Artículo 30. Regímenes constitucionales federales o no unitarios

Reconociendo que los acuerdos internacionales vinculan asimismo a las Partes, independientemente de sus sistemas constitucionales, se aplicarán las siguientes disposiciones a las Partes que tengan un régimen constitucional federal o no unitario:

a) por lo que respecta a las disposiciones de la presente Convención cuya aplicación incumba al poder legislativo federal o central, las obligaciones del gobierno federal o central serán idénticas a las de las Partes que no son Estados federales;

b) por lo que respecta a las disposiciones de la presente Convención cuya aplicación sea de la competencia de cada una de las unidades constituyentes, ya sean Estados, condados, provincias o cantones que, en virtud del régimen constitucional de la federación, no estén facultados para tomar medidas legislativas, el gobierno federal comunicará con su dictamen favorable esas disposiciones, si fuere necesario, a las autoridades competentes de la unidades constituyentes, ya sean Estados, condados, provincias o cantones, para que las aprueben.

\section{Artículo 31. Denuncia}

1. Toda Parte en la presente Convención podrá denunciarla.

2. La denuncia se notificará por medio de un instrumento escrito, que se depositará ante el Director General de la UNESCO.

3. La denuncia surtirá efecto 12 meses después de la recepción del instrumento de denuncia. No modificará en modo alguno las obligaciones financieras que haya de asumir la Parte denunciante hasta la fecha en que su retirada de la Convención sea efectiva.

\section{Artículo 32. Funciones del depositario}

El Director General de la UNESCO, en su calidad de depositario de la presente Convención, informará a los Estados Miembros de la Organización, los Estados que no son miembros, las organizaciones de integración económica regional mencionadas en el Artículo 27 y las Naciones Unidas, del depósito de todos los instrumentos de ratificación, aceptación, aprobación o adhesión contemplados en los Artículos 26 y 27 y de las denuncias previstas en el Artículo 31.

Artículo 33. Enmiendas

1. Toda Parte en la presente Convención podrá 
proponer enmiendas a la misma mediante comunicación dirigida por escrito al Director General. Éste transmitirá la comunicación a todas las demás Partes. Si en los seis meses siguientes a la fecha de envío de la comunicación la mitad por lo menos de las Partes responde favorablemente a esa petición, el Director General someterá la propuesta al examen y eventual aprobación de la siguiente reunión de la Conferencia de las Partes.

2. Las enmiendas serán aprobadas por una mayoría de dos tercios de las Partes presentes y votantes.

3. Una vez aprobadas, las enmiendas a la presente Convención deberán ser objeto de ratificación, aceptación, aprobación o adhesión por las Partes.

4. Para las Partes que hayan ratificado, aceptado o aprobado enmiendas a la presente Convención, o se hayan adherido a ellas, las enmiendas entrarán en vigor tres meses después de que dos tercios de las Partes hayan depositado los instrumentos mencionados en el párrafo 3 del presente artículo. A partir de ese momento la correspondiente enmienda entrará en vigor para cada Parte que la ratifique, acepte, apruebe o se adhiera a ella tres meses después de la fecha en que la Parte haya depositado su instrumento de ratificación, aceptación, aprobación o adhesión.

5. El procedimiento previsto en los párrafos 3 y 4 no se aplicará a las enmiendas al Artículo 23 relativo al número de miembros del Comité Intergubernamental. Estas enmiendas entrarán en vigor en el momento mismo de su aprobación.

6. Los Estados u organizaciones de integración económica regionales mencionadas en el Artículo 27, que pasen a ser Partes en esta Convención después de la entrada en vigor de enmiendas de conformidad con el párrafo 4 del presente artículo y que no manifiesten una intención en sentido contrario serán considerados:

a) Partes en la presente Convención así enmendada; y

b) Partes en la presente Convención no enmendada con respecto a toda Parte que no esté obligada por las enmiendas en cuestión.

Artículo 34. Textos auténticos
La presente Convención está redactada en árabe, chino, español, francés, inglés y ruso, siendo los seis textos igualmente auténticos.

\section{Artículo 35. Registro}

De conformidad con lo dispuesto en el Artículo 102 de la Carta de las Naciones Unidas, la presente Convención se registrará en la Secretaría de las Naciones Unidas a petición del Director General de la UNESCO.

\section{ANEXO}

\section{Procedimiento de conciliación}

Artículo 1. Comisión de Conciliación

Se creará una Comisión de Conciliación a solicitud de una de las Partes en la controversia. A menos que las Partes acuerden otra cosa, esa Comisión estará integrada por cinco miembros, dos nombrados por cada Parte interesada y un Presidente elegido conjuntamente por esos miembros.

\section{Artículo 2. Miembros de la Comisión}

En las controversias entre más de dos Partes, aquellas que compartan un mismo interés nombrarán de común acuerdo a sus respectivos miembros en la Comisión. Cuando dos o más Partes tengan intereses distintos o haya desacuerdo en cuanto a las Partes que tengan el mismo interés, nombrarán a sus miembros por separado.

\section{Artículo 3. Nombramientos}

$\mathrm{Si}$, en un plazo de dos meses después de haberse presentado una solicitud de creación de una Comisión de Conciliación, las Partes no hubieran nombrado a todos los miembros de la Comisión, el Director General de la UNESCO, a instancia de la Parte que haya presentado la solicitud, procederá a los nombramientos necesarios en un nuevo plazo de dos meses.

\section{Artículo 4. Presidente de la Comisión}

Si el Presidente de la Comisión de Conciliación no hubiera sido designado por ésta dentro de los dos meses siguientes al nombramiento del último miembro de la Comisión, el Director General de la 
UNESCO, a instancia de una de las Partes, procederá a su designación en un nuevo plazo de dos meses.

Artículo 5. Fallos

La Comisión de Conciliación emitirá sus fallos por mayoría de sus miembros. A menos que las Partes en la controversia decidan otra cosa, determinará su propio procedimiento. La Comisión formulará una propuesta de solución de la controversia, que las Partes examinarán de buena fe.

Artículo 6. Desacuerdos

Cualquier desacuerdo en cuanto a la competencia de la Comisión de Conciliación será zanjado por la propia Comisión. 